\title{
Intraoperative Optical Coherence Tomography-Assisted 27-Gauge Vitrectomy in Eyes with Vitreoretinal Diseases
}

\author{
Hiroshi Kunikata ${ }^{a, b} \quad$ Toru Nakazawa ${ }^{a-c}$ \\ Departments of aphthalmology, ${ }^{\mathrm{b}}$ Retinal Disease Control and ${ }^{\mathrm{C}}$ Advanced Ophthalmic \\ Medicine, Tohoku University Graduate School of Medicine, Sendai, Japan
}

\section{Key Words}

Intraoperative optical coherence tomography - Twenty-seven-gauge vitrectomy . Vitreoretinal disease $\cdot$ Triamcinolone acetonide $\cdot$ Microincision vitrectomy surgery

\begin{abstract}
Objective: To report intraoperative optical coherence tomography (iOCT)-assisted 27-gauge microincision vitrectomy surgery (MIVS) in eyes with vitreoretinal disease. Methods: A retrospective, interventional case series performed at a single center, including 6 eyes with retinal disease that underwent IOCT-assisted 27-gauge MIVS. Results: The advantages of IOCT were most notable when it was used to evaluate, in real time, different macular areas: the premacula, in vitreomacular traction or epiretinal membrane; the intra-macula, in macular edema or macular hole; and the sub-macula, in macular detachment. Real-time imaging and the minimization of shadows cast on the underlying tissues by the 27-gauge instrumentation made it possible to quickly select the best procedure at each critical juncture of the surgery. No patients experienced any complications. Conclusion: Real-time iOCT imaging during 27gauge MIVS provided excellent intraoperative visualization of retinal tissues without causing significant obstructions to the surgeon. The positive feedback from the system allowed the surgeon to better judge the necessity of additional surgical procedures. $02015 \mathrm{~S}$. Karger AG, Basel
\end{abstract}


Kunikata and Nakazawa: Intraoperative Optical Coherence Tomography-Assisted 27Gauge Vitrectomy in Eyes with Vitreoretinal Diseases

\section{Introduction}

Intraoperative optical coherence tomography (iOCT) is a recent innovation that has been introduced as a surgical instrument for clinical procedures in the cornea and vitreous [1-8]. There are two types of iOCT currently available for this purpose: a small, handheld system [2, 3] and a microscope-integrated system [4-8]. A recent report has shown that microscope-integrated iOCT is an effective surgical instrument and allows surgeons to visualize the surgical site in real time without the need to interrupt the procedure [9]. Another report has shown that 27-gauge microincision vitrectomy surgery (MIVS) [10], with its very fine-shafted instruments, can reduce the invasiveness of vitreous surgery. However, there has been no report on the effectiveness of combining these systems. Furthermore, neither the usefulness of the iOCT system itself nor its compatibility with the current best techniques for vitreous surgery have been definitively established. Thus, this is the first report on iOCT-assisted 27-gauge MIVS in eyes with vitreoretinal disease.

\section{Methods}

This was a retrospective, interventional case series performed at a single center. Six eyes of 6 patients were selected from patients with retinal disease who underwent 27-gauge MIVS (Alcon Laboratories; Fort Worth, Tex., USA) with iOCT. We performed intraoperative imaging of the vitreous and retina with the RESCAN 700 (Carl Zeiss Meditec AG, Jena, Germany), a microscope-integrated iOCT system. The RESIGHT (Carl Zeiss Meditec) lens system or a vitrectomy contact lens (HHV Dispo, Type 1d, HOYA, Tokyo, Japan) were used for surgical and iOCT visualization. To determine the precise status of the macula, iOCT scanning was used to visualize the macula in real time before, during and after treatment. The surgeon (H.K.) selected the scan location with a foot pedal control, while an assistant simultaneously input the scan length and angle with a video monitor display system, following the surgeon's instructions. All patients were followed for more than 3 months after surgery. After resecting the vitreal core, $4 \mathrm{mg}$ of triamcinolone acetonide (TA; MaQaid, Wakamoto Pharmaceutical Co., Ltd., Tokyo, Japan) was injected into the vitreous cavity to determine if a posterior vitreous detachment was present. If it was not present, we created one with a 27-gauge cutter. After shaving the peripheral gel, we removed the epiretinal membrane (ERM) or internal limiting membrane (ILM), removed any subretinal fluid, performed fluid-air exchange, or transplanted an ILM graft from another region, if needed. In all patients, we only used iOCT when we determined that it was in the best interests of the patient. The exact surgical procedures used varied according to the type of vitreoretinal disease.

\section{Results}

The preoperative and intraoperative demographics and postoperative courses of the 6 patients are shown in table 1. Imaging with iOCT was used to evaluate macular status in suspected cases of macular edema (case No. 1), vitreomacular traction (case No. 2), ERM (case No. 3), macular detachment (cases No. 4 and 5), or macular hole (case No. 6). These intraoperative findings improved the surgeon's intraoperative judgment in all cases (table 1 and fig. 1; see online suppl. video, www.karger.com/doi/10.1159/000437014). Particularly, iOCT helped determine the necessity of additional procedures, such as removal of the ERM or ILM, removal of subretinal fluid, fluid-air exchange, or further transplantation of an ILM 
Kunikata and Nakazawa: Intraoperative Optical Coherence Tomography-Assisted 27Gauge Vitrectomy in Eyes with Vitreoretinal Diseases

graft. We also found that the sparing use of injected TA usefully enhanced the contrast of the images. No patient experienced any adverse events.

\section{Discussion}

The advantages of iOCT in vitreous surgery were most notable when it was used to evaluate different areas of the macula: the pre-macula, in vitreomacular traction or ERM; the intra-macula, in macular edema or macular hole; and the sub-macula, in macular detachment. The expert use of iOCT should allow surgeons to avoid performing unnecessary procedures, particularly the removal of the ILM or fluid-air exchange, and lead to minimally invasive, optimal interventions. Furthermore, to ensure that real-time iOCT imaging during macular surgery is as clear as possible, it is important that the metallic surgical instrumentation should be as fine as possible, in order to limit shadowing on the underlying tissues and allow visualization of the instrument-tissue interaction. In our experience, using iOCT with a 25 -gauge system causes shadowing on the underlying tissues that is relatively greater than the shadowing caused by 27 -gauge instruments. For this reason, we believe that 27 -gauge MIVS, which uses the smallest currently available shafts, is the most suitable for vitrectomy with iOCT. The combination of 27-gauge MIVS and iOCT is a technically feasible and safe technique for use in eyes with vitreoretinal disease. We do not consider that there are any particular devices or techniques that can enhance iOCT imaging during surgery, other than the sparing use of TA and the skill of the surgeon in using the foot pedal accurately. It is important that TA is used only sparingly in IOCT, as dense TA or large TA clots can cause unfavorable shadowing on the underlying tissues.

Our study was somewhat limited by a small sample size and by the current limitations of the iOCT device itself, which has a display resolution lower than other currently used OCT devices and depends on the accuracy of the surgeon's skill in using the foot pedal. However, this system allowed real-time imaging and provided positive feedback that allowed the surgeon to better judge the necessity of additional surgical procedures, while causing minimal obstruction to the surgeon and enabling excellent intraoperative visualization of retinal tissues.

\section{Acknowledgements}

This paper was supported in part by a JST grant from JSPS KAKENHI Grants-in-Aid for Scientific Research (B) (T.N. 26293372), for Scientific Research (C) (H.K. 26462629), and for Exploratory Research (T.N. 26670751). The funders had no role in the design and conduct of the study; collection, management, analysis, and interpretation of the data; preparation, review, or approval of the manuscript, and decision to submit the manuscript for publication.

\section{Statement of Ethics}

This study conformed to the tenets of the Declaration of Helsinki and was approved by the Institutional Review Board of the School of Medicine, Tohoku University. 
Kunikata and Nakazawa: Intraoperative Optical Coherence Tomography-Assisted 27Gauge Vitrectomy in Eyes with Vitreoretinal Diseases

\section{Disclosure Statement}

The authors declare that they have no competing interests, no proprietary interests, and no other disclosures.

\section{References}

1 Geerling G, Muller M, Winter C, et al: Intraoperative 2-dimensional optical coherence tomography as a new tool for anterior segment surgery. Arch Ophthalmol 2005;123:253-257.

-2 Dayani PN, Maldonado R, Farsiu S, Toth CA: Intraoperative use of handheld spectral domain optical coherence tomography imaging in macular surgery. Retina 2009;29:1457-1468.

- 3 Ehlers JP, Kernstine K, Farsiu S, Sarin N, Maldonado R, Toth CA: Analysis of pars plana vitrectomy for optic pit-related maculopathy with intraoperative optical coherence tomography: a possible connection with the vitreous cavity. Arch Ophthalmol 2011;129:1483-1486.

4 Ray R, Baranano DE, Fortun JA, et al: Intraoperative microscope-mounted spectral domain optical coherence tomography for evaluation of retinal anatomy during macular surgery. Ophthalmology 2011;118:2212-2217.

5 Pichi F, Alkabes M, Nucci P, Ciardella AP: Intraoperative SD-OCT in macular surgery. Ophthalmic Surg Lasers Imaging 2012;43:S54-S60.

6 Ehlers JP, Ohr MP, Kaiser PK, Srivastava SK: Novel microarchitectural dynamics in rhegmatogenous retinal detachments identified with intraoperative optical coherence tomography. Retina 2013;33:1428-1434.

7 Ehlers JP, Xu D, Kaiser PK, Singh RP, Srivastava SK: Intrasurgical dynamics of macular hole surgery: an assessment of surgery-induced ultrastructural alterations with intraoperative optical coherence tomography. Retina 2014;34:213-221.

-8 Ehlers JP, Tam T, Kaiser PK, Martin DF, Smith GM, Srivastava SK: Utility of intraoperative optical coherence tomography during vitrectomy surgery for vitreomacular traction syndrome. Retina 2014;34:1341-1346.

-9 Ehlers JP, Kaiser PK, Srivastava SK: Intraoperative optical coherence tomography using the RESCAN 700: preliminary results from the DISCOVER study. Br J Ophthalmol 2014;98:1329-1332.

10 Oshima Y, Awh CC, Tano Y: Self-retaining 27-gauge transconjunctival chandelier endoillumination for panoramic viewing during vitreous surgery. Am J Ophthalmol 2007;143:166-167. 
Kunikata and Nakazawa: Intraoperative Optical Coherence Tomography-Assisted 27-

Gauge Vitrectomy in Eyes with Vitreoretinal Diseases

Table 1. Description of patients who underwent iOCT-assisted 27-gauge vitrectomy

\begin{tabular}{|c|c|c|c|c|c|c|}
\hline $\begin{array}{l}\text { Patient } \\
\text { No./sex/ } \\
\text { age, years }\end{array}$ & Eye & $\begin{array}{l}\text { Ophthalmological } \\
\text { diagnosis }\end{array}$ & $\begin{array}{l}\text { Pre- } \\
\text { operative } \\
\text { decimal VA }\end{array}$ & $\begin{array}{l}\text { Post- } \\
\text { operative } \\
\text { decimal VA }\end{array}$ & iOCT findings & $\begin{array}{l}\text { Impact on surgeon's intraopera- } \\
\text { tive judgement }\end{array}$ \\
\hline 1/M/85 & $\mathrm{RE}$ & $\begin{array}{l}\text { VH due to branch retinal } \\
\text { vein occlusion }\end{array}$ & HM & 1.2 & $\begin{array}{l}\text { Confirmation that no macular } \\
\text { edema or ERM was present after } \\
\text { removal of the VH }\end{array}$ & $\begin{array}{l}\text { Surgeon performed no addi- } \\
\text { tional procedures, such as re- } \\
\text { moval of the ERM or ILM }\end{array}$ \\
\hline $2 / F / 64$ & $\mathrm{RE}$ & $\begin{array}{l}\text { Vitreomacular traction } \\
\text { syndrome }\end{array}$ & 0.06 & 0.4 & $\begin{array}{l}\text { Confirmation that ERM remained } \\
\text { after the release of vitreomacular } \\
\text { traction }\end{array}$ & $\begin{array}{l}\text { Surgeon removed the ERM and } \\
\text { ILM }\end{array}$ \\
\hline $3 / \mathrm{M} / 84$ & $\mathrm{RE}$ & ERM (lamellar MH) & 0.5 & 0.8 & $\begin{array}{l}\text { Confirmation that no iatrogenic } \\
\text { MH was created during or after } \\
\text { removal of the ERM and ILM }\end{array}$ & $\begin{array}{l}\text { Surgeon performed no addi- } \\
\text { tional procedures, such as FAX }\end{array}$ \\
\hline $4 / \mathrm{M} / 54$ & $\mathrm{RE}$ & $\begin{array}{l}\text { Macula-on rhegmatog- } \\
\text { enous retinal detachment } \\
\text { with VH }\end{array}$ & 0.3 & 1.2 & $\begin{array}{l}\text { Confirmation that macular de- } \\
\text { tachment did not occur during } \\
\text { FAX }\end{array}$ & $\begin{array}{l}\text { Surgeon performed no addi- } \\
\text { tional procedures, such as re- } \\
\text { moval of preretinal fluid, after } \\
\text { successful endophotocoagula- } \\
\text { tion }\end{array}$ \\
\hline $5 / F / 73$ & LE & $\begin{array}{l}\text { Retinal detachment due to } \\
\text { MH in highly myopic eye }\end{array}$ & 0.01 & 0.04 & $\begin{array}{l}\text { Confirmation that removal of } \\
\text { subretinal fluid from the macula } \\
\text { was successful during FAX }\end{array}$ & $\begin{array}{l}\text { Surgeon completed the removal } \\
\text { of subretinal fluid through the } \\
\text { MH }\end{array}$ \\
\hline $6 / M / 55$ & $\mathrm{RE}$ & $\begin{array}{l}\text { MH after ERM removal in } \\
\text { highly myopic eye }\end{array}$ & 0.5 & 0.8 & $\begin{array}{l}\text { Confirmation that the autologous } \\
\text { ILM was properly placed in the } \\
\text { fovea during and after FAX }\end{array}$ & $\begin{array}{l}\text { Surgeon performed no addi- } \\
\text { tional procedures, such as re- } \\
\text { transplantation of another graft } \\
\text { from another region }\end{array}$ \\
\hline
\end{tabular}

$\mathrm{M}=$ Male; $\mathrm{F}$ = female; $\mathrm{RE}$ = right eye; $\mathrm{LE}$ = left eye; $\mathrm{VA}$ = visual acuity; $\mathrm{VH}=$ vitreous hemorrhage; $\mathrm{HM}$ = hand movement; $\mathrm{ERM}=$ epiretinal membrane; ILM = internal limiting membrane; $\mathrm{MH}$ = macular hole; FAX = fluid-air exchange. 
Kunikata and Nakazawa: Intraoperative Optical Coherence Tomography-Assisted 27Gauge Vitrectomy in Eyes with Vitreoretinal Diseases

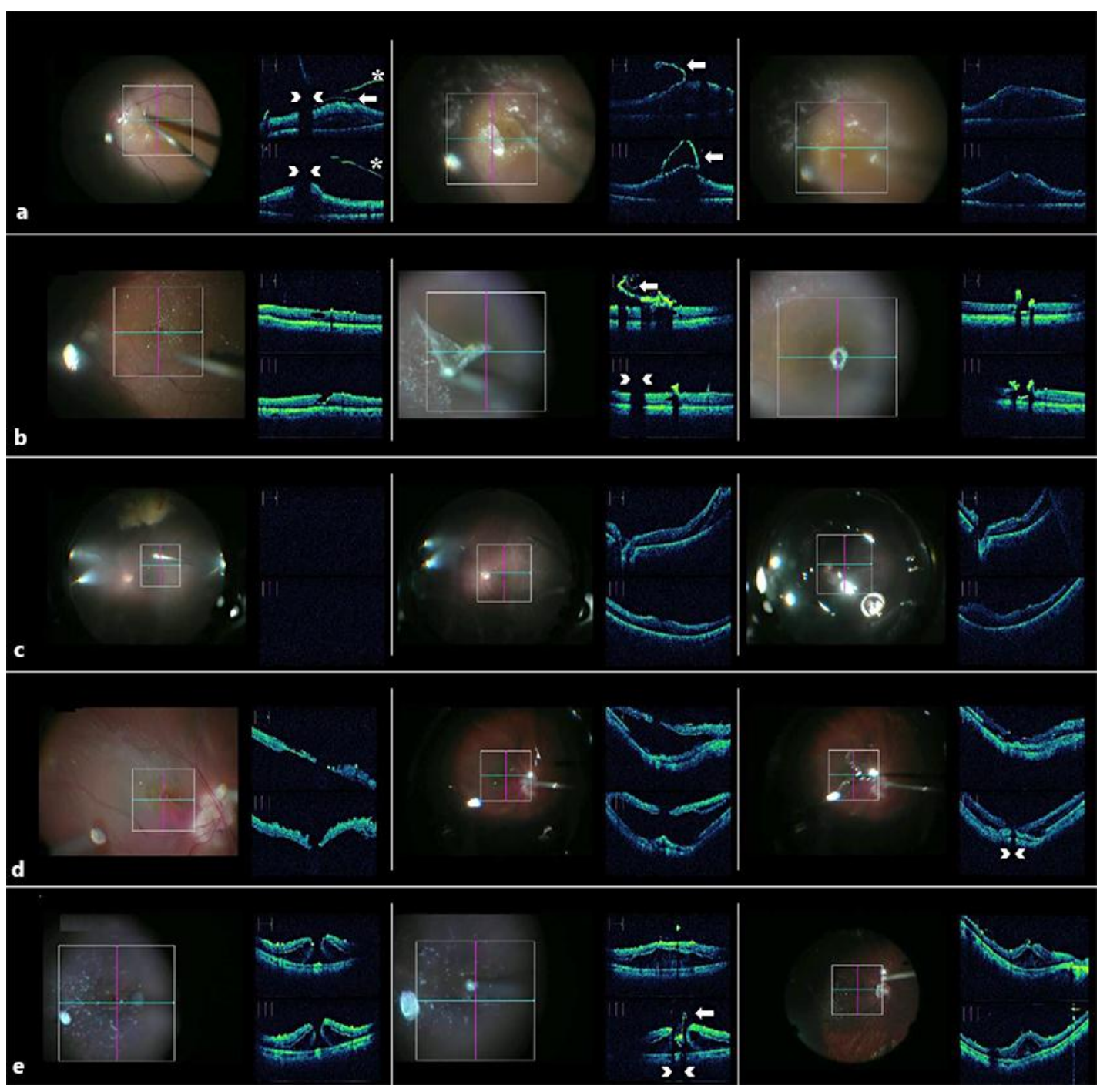

Fig. 1. Pairs of images showing the effect of real-time feedback on surgical course in 6 patients. Images were obtained simultaneously with intraoperative surgical photography (left side of each pair) and posterior-segment iOCT (right side of each pair). The green and red lines in the photographs indicate axial and sagittal B-scans in the OCT images, respectively. a Case 2. Vitreomacular traction (VMT) syndrome. The VMT (asterisks) was released, with minimal shadowing (arrowheads) from the 27-gauge instrumentation on the underlying tissues (left image pair). A remnant ERM (arrows) was present, which was removed successfully (left and middle pairs). Finally, no remaining remnant ERM was present (right pair). b Case 3. ERM (lamellar macular hole, MH). An MH was not present before ERM and ILM peeling (left image pair). The ERM (arrow) was carefully peeled with minimal shadowing (arrowheads) from the 27-gauge instrumentation on the underlying tissues (middle pair). Hyperreflective material on the top of the fovea, which appeared as a whitish ring in fundus photography, indicated the presence of triamcinolone particles on the residual ILM, with no post-ERM removal iatrogenic MH (right pair). c Case 4. Macula-on rhegmatogenous retinal detachment (RRD) with vitreous hemorrhage (VH). The VH was removed (left image pair) and the surgeon confirmed that there was no macular detachment (middle pair). RRD repair was performed with confirmation that no macular detachment occurred during fluid-air exchange (FAX) and cryoretinopexy (right pair). d Case 5. Retinal detachment due to $\mathrm{MH}$ in a highly myopic eye. An open $\mathrm{MH}$ was present before ILM peeling (left image pair). FAX was performed after ILM peeling (middle pair). Subretinal fluid was successfully removed through the MH during and after FAX with minimal shadowing (arrowheads) from the 27-gauge instrumentation on the underlying tissues (right pair). e Case 6. MH after 
Kunikata and Nakazawa: Intraoperative Optical Coherence Tomography-Assisted 27Gauge Vitrectomy in Eyes with Vitreoretinal Diseases

ERM and ILM removal in a highly myopic eye. A relatively large MH was present without an ILM (left image pair). An autologous ILM (arrow) was transplanted from another region with minimal shadowing (arrowheads) from the 27-gauge instrumentation on the underlying tissues (middle pair). Proper placement of the autologous ILM graft in the fovea during and after FAX was confirmed (right pair). 